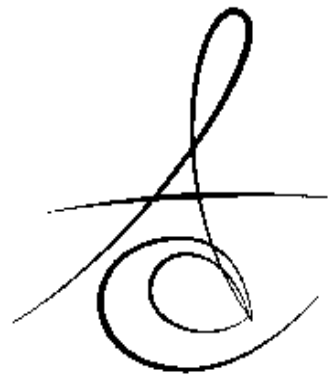

Makale Kodu/Article code: 3528

Makale Gönderilme tarihi: 20.12.2017

Kabul Tarihi: 19.04.2018

\section{KÖK KANAL ŞEKİLLENDİRİLMESİNDE REHBER YOL OLUŞTURMANIN ÖNEMI}

\author{
IMPORTANCE OF A CREATING GLIDE PATH ON ROOT CANAL \\ PREPARATION
}

\author{
Dr. Öğr. Üyesi Damla ÖzSU KIRICI*
}

\section{öz}

Kök kanal şekillendirilmesi endodontik tedavinin en önemli aşamalarındandır. Nikel Titanyum(Ni-Ti) döner aletler kök kanal şekillendirilmesinde el ile kullanılan aletler ile karşılaştırıldığında daha az zamanda daha ideal bir şekillendirme sağlamaktadır. Fakat döner aletlerin daha güvenilir kullanılması için bu aletlerle şekillendirme yapmadan önce rehber yol oluşturulması tavsiye edilmektedir. Rehber yol oluşturulmaması basamak, alet kırılması, zip, kök kanalından sapma ve perforasyon gibi sonuçlar doğurabilir. Eğri köklü dişlerde rehber yol $\mathrm{K}$ tipi eğe ve $\mathrm{Ni}-\mathrm{Ti}$ rehber yol eğeleri ile oluşturulmaktadır. Çalışmalar Ni-Ti eğeler ile rehber yol oluşturmanın $\mathrm{K}$ tipi eğelere göre daha kısa sürede ve daha az hata oluşturduğunu göstermiştir. Bu derlemenin amacı, rehber yol oluşturmanın eğri kök kanallarının şekillendirmesindeki önemini vurgulamak ve rehber yol oluştururken kullanılan yöntem ve sistemleri irdelemektir.

Anahtar Kelimeler: Rehber yol, Nikel Titanyum, Kök kanal şekillendirmesi

\section{ABSTRACT}

Shaping of root canals is the most important aspect of endodontic therapy. Nickel-titanium (Ni-Ti) rotary instruments represent a new approach for the ideal preparation of canals in curved canals in a shorter time as compared with manual instrumentation. Creating a glidepath is recommended before using $\mathrm{Ni}$ Ti rotary instrumentation to shaping of curved root canals safely. The lack of glide path establishment may result in ledge formation, separated of instrument, transportation, zip formation and perforation. Glide path enlargement can be carried out with stainless steel $\mathrm{K}$-files or $\mathrm{Ni}$-Ti glide path files. Studies have shown that glide path enlargement with $\mathrm{Ni}$-Ti files is faster and causes less procedural errors than hand K-files. Aim of this paper is to emphasize the importance of glide path and inform methods of preparation of glide path and file systems.

Keywords: Glide Path, Nickel-Titanium, Root canal preparation.

Kök kanal sistemleri, anatomileri açısından fark-

\section{GÍRİ̧}

Endodontik tedavinin en önemli aşamalarından biri olan kök kanal şekillendirmesinin temel amacı kök kanal sisteminden bakterilerin eliminasyonunu sağlamak, debrisi uzaklaştırmak ve kök kanal boşluğunu 3 boyutlu ve hermetik bir şekilde doldurmaktır. ${ }^{1}$

Kök kanal şekillendirilmesi sırasında perforasyon, kök kanal transportasyonu, basamak oluşumu ve alet kırıması gibi bazı komplikasyonlarla karşılaşılabilinir. ${ }^{2-5}$ lılık gösterebilir ve bu farklılıklardan dolayı kök kanal şekillendirmesi sırasında hekim bazı zorluklarla karşılaşabilir. ${ }^{6,7}$ Özellikle eğri kök kanallarının şekillendirme işlemi sırasında orijinal kanal seyrinin korunamaması sonucunda kaldırılamayan enfekte doku artıkları ve bakteriler kök kanal tedavisinde başarısızlığa neden olabilmektedir. ${ }^{8}$ Diğer taraftan bu tip dişlerde perforasyon, kök kanal transportasyonu, basamak oluşumu ve alet kırılması gibi komplikasyonların oluşma riski daha fazladır. ${ }^{9}$ Bu nedenle kök kanalını şekillendirmeye başlarken, kanala ilk girişte özellikle apikal bölgede

\footnotetext{
* Akdeniz Üniversitesi Dişhekimliği Fakültesi, Endodonti AD, Antalya.

** Atatürk Üniversitesi Dişhekimliği Fakültesi, Endodonti AD, Erzurum.
} 
güvenli ve etkili ilerleme sağlanmak isteniyorsa kanala ilk girişte kullanılan başlangıç aletlerinin esnek ve küçük numaralı olması gerekmektedir. ${ }^{10}$

Yeni nesil üretilen $\mathrm{Ni}$-Ti döner aletler ile şekillendirme sırasında oluşabilecek komplikasyonlar en aza indirilmeye çalışılmıştır. Fakat bu aletleri güvenli bir şekilde kullanmak için de koronal genişletme ve ön genişletme (preflaring) yaparak rehber yol (glide path) oluşturmamız tavsiye edilmektedir. ${ }^{11-14}$

West, rehber yolu kanal girişinden kök kanalının fizyolojik sonlanma yerine kadar giden pürüzsüz ilerleyen bir tünel olarak tanımlamaktadır. Eğenin kanalı, kanalın girişinden apikale kadar kesintisiz bir şekilde takip etmesi sağlandığında rehber yol başarıyla oluşturulur. ${ }^{15}$ Rehber yol ile döner enstrümanlar kanalı pasif bir şekilde takip eder. Rehber yol kök ucundaki açıklığı belirlemeyi sağlar ve sonrasında başarılı bir kök kanal dolumu yapılabilir. ${ }^{16}$

$\mathrm{Ni}$-Ti döner aletlerin çoğu kesici olmayan uç yapısındadır ve kök kanalında ilk alet olarak kullanılmasına uygun dizayn edilmemiştir. ${ }^{17,18}$ Bergmans ve ark. $^{18}$ kök kanal şekillendirmesi sırasında döner alet kullanılmadan önce kanalda el eğesinin kullanılması gerektiğini bildirmişlerdir.

Roland ve ark. ${ }^{19}$ koronal preflaring yapılmasının alet kırık insidansını azalttığını göstermişlerdir. Küçük numaralı el aletlerinin kullanılması kanal açıklığını belirlenmesini ve döner aletlerin kanal içinde güvenilir bir şekilde kullanılmasını sağlar. Peters ve ark. ${ }^{20}$ çok dar kanala sahip çekilmiş dişlerde yaptıkları çalışmada el eğeleri ile rehber yol oluşturduklarında dişlerde çok dar kanallar olmasına rağmen hiçbir aletin kırılmadığını bildirmişlerdir. Etkili bir rehber yol oluşturulması torsiyonel stresi azaltarak döner enstrümanların ömrünü uzatmaktadır.

\section{Rehber Yol Oluşturma Yöntemleri}

Rehber yol oluşturmak için farklı yöntemler vardır.

- K-tipi eğe ile

- Resiprokal hareket yapan başlıklarla kullanılan K tipi eğe ile

- Döner aletler ile kullanılan Ni-Ti eğeleri ile

\section{K tipi eğe ile rehber yol oluşturma}

Birçok araştırıcı paslanmaz çelik $\mathrm{K}$ tipi eğeler ile kullanarak rehber yol oluşturulmasını tavsiye etmektedir.

K-tipi eğe ile rehber yol oluşturmak döner $\mathrm{Ni}$-Ti eğelerle karşılaştırıldığında: ${ }^{21}$
- K-tipi eğe ile parmak hassasiyeti daha iyi sağlanır,

- Eğenin kırılma potansiyeli daha azdır,

- K-tipi eğeler kanaldan çıkartıldığında deforme olduysa gözle görülür ve kanalda kurvatür varsa hekim daha dikkatli olur,

- Daha ucuzdurlar,

- Kullanırken başlığa intiyaç duyulmaz.

Berutti ve ark. ${ }^{11,22}$ rehber yol oluşturulduktan sonra kanal çapının kullanılacak döner enstrüman çapından bir fazla olması gerektiğini savunmuşlardır. West $10 \mathrm{~K}$ tipi eğenin kanalda serbest bir şekilde olmasını tavsiye etmekte ve 10 numaralı $\mathrm{K}$ tipi eğeden daha büyük eğelerle rehber yol oluşturulacaksa Roane'nin tavsiye ettiği gibi basamak oluşma riskini azaltmak için balanced force tekniği ile genişletme yapılması gerektiğini belirtmektedir. ${ }^{22}$

El eğeleri ile rehber yol oluşturmanın klinisyenin yorgunluğu, el yorgunluğu, rehber yol oluşturulurken zaman alması, büyük numaralı eğelerin kulanımının kanalda komplikasyon oluşturma riskini doğurması, orjinal kanal anatomisinde değişiklik oluşturabilmesi gibi dezavantajları vardır. ${ }^{12}$

Resiprokal hareket yapan başlıklarla kullanılan $\mathrm{K}$ tipi eğe

Bu sistemde K tipi küçük numaralı eğeler resiprokal hareket yapan başlıklara takılarak rehber yol oluşturulmak için kullanılır. K tipi eğe önce el ile kullanılarak kanal boyu tespit edilir ve sonra başlığa takılır. Başık aşağı ve yukarı 1 ile 3 mm arasında her kanalda ortalama 15-30 saniye vertikal olarak hareket ettirilir. Kompleks kanallarda ilerlemek için paslanmaz çelik ve karbon çelikte dizayn edilmiş Pathfinder eğeler M4 resiprokal çalışan başlıklara takılarak kullanılabilir.

\section{Bu sistemin avantajları: ${ }^{23}$}

- Şekillendirme zamanı azalır,

- Klinisyen daha az yorulur,

- El yorgunluğu daha az olur,

- Ni-Ti döner alet sistemine göre daha az alet kırılması olur,

\section{Dezavantajları:}

- Başlığa ihtiyaç vardır

- 15 numaralı $\mathrm{K}$ tipi eğeden büyük eğeler kullanıldığında apikal transportasyon riski vardır,

- Klinisyen olması gerektiğinden daha fazla kanalda çalışırsa fazla dentin kaldırma riski doğabilir,

- Başlık apikale doğru kuvvetle itilirse apikalden debris taşma riski vardır,

- Parmak hassasiyeti azalır. 
Döner aletler ile kullanılan $\mathrm{Ni}$-Ti eğeler ile rehber yol oluşturma

Günümüzde döner aletler ile rehber yol oluşturmak için birçok sistem üretilmiştir ve bu sistemleri geliştirmek için çalışmalar devam etmektedir.

Bu yöntemin avantajları: ${ }^{11,23}$

- Şekillendirme zamanının kısalması,

- Basamak, zip ve transportasyon gibi komplikasyonların azalması,

- Orijinal kanal anatomisinin daha iyi korunabilmesi,

- Klinisyenin ve el yorgunluğunun azalması,

- Apikalden debris çıkışının azalması,

- Postoperatif ağrının daha az olması, Dezavantajları:

- Pahalıdır,

- Eğe kırılma riski fazladır,

- Parmak hassasiyeti daha azdır. Ti eğeler

Rehber yol oluşturmak için kullanılan Ni-

Path File Sistemi (Dentsply Maillefer, Ballaigues, İsviçre):

Rehber yolu (glide path) mekanik olarak oluşturmak için geliştirilen PathFile $\mathrm{Ni} \mathrm{Ti}$ döner aletleri Dentsply Maillefer tarafından üretilmiştir. Bu döner aletler ProTaper Universal döner alet sistemiyle kombine kullanılabildikleri gibi diğer döner alet sistemleri ile de rehber yol oluşturmak için kullanılabilmektedir. Üretici firma tarafından dar, uzun ve eğri kanallarda büyük açılı eğeler kullanılmadan önce bu sistemin kullanılması tavsiye edilmiştir. Eğelerin uç çapları 0.13 , 0.16 ve $0.19 \mathrm{~mm}$ 'dir.Eğelerin uçları kesici değildir, basamak ve zip oluşumunu önlemek için yuvarlatılmıştır. Eğelerin kesiti karedir. Kare kesit eğelerin torsiyonel streslere karşı daha dirençli olmalarını sağlar.Dört kesici kenarı vardır. Bu özelliği eğenin kesme etkinliğini arttırır. Sistem 3 farklı çapta ve 21, 25 ve $31 \mathrm{~mm}$ uzunluklarda $\mathrm{Ni}-\mathrm{Ti}$ döner eğelerden oluşmaktadır. Aletlerin esnekliği $\mathrm{Ni}-\mathrm{Ti}$ alaşımı ve 0.02 lik taper açısıyla sağlanmıştır. PathFile döner aletler 300 rpm'de ve $2 \mathrm{~N} / \mathrm{cm}^{\prime}$ lik tork derecesinde kullanılması üretici firma tarafından önerilmiştir. Fransa)

G Files Sistemi (Micro Mega, Besançon,

Micro Mega'nın 2011 yılında satışa sunduğu bu sistem mekanik olarak rehber yol oluşturmak için üretilmiştir. G Files sisteminin karmaşık anatomiye sahip, dar ve kalsifiye kanallarda kullanılması amaçlanmıştır ve bütün Ni-Ti döner sistemlerle kombine kullanılabilir. Eğelerin uç çapları 0.12 ve 0.17 mm'dir. G Files döner aletleri 21, 25 ve $31 \mathrm{~mm}$ boylarında 3 farklı boyuta sahiptirler. Yüzey cilalama (electropolishing) işlemine tabi tutulmuştur. Enstrümanın uzunluğu boyunca çapraz kesit farklılar göstermektedir. 3 kesici kenar 3 farklı çapta kanalla ilişki halindedir. Kesici olmayan uç yapısı vardır. Eğelerin $400 \mathrm{rpm}$ hızla ve $1.2 \mathrm{~N} / \mathrm{cm}$ tork ayarında kullanılması üretici firma tarafından önerilmiştir.

\section{İsviçre)}

ProGlider (Dentsply Maillefer, Ballaigues,

ProGlider eğesi Dentsply firmasının rehber yol oluşturmak için PathFile eğelerden sonra ürettikleri tek eğe ile rehber yolu oluşturmak için satışa sunduğu eğedir. ${ }^{24}$ Eğe 21,25 ve $31 \mathrm{~mm}$ uzunluktaki üç farklı boyda üretilmiştir. Eğenin uç çapı $0.16 \mathrm{~mm}$ 'dir ve 0.2 apikal taper açısına sahiptir.

Eğe M-Wire Ni-Ti alaşımı kullanılarak üretilmiştir ve bu şekilde eğenin daha esnek ve dayanıklı olması sağlanmıştır. ProGlider eğeleri kök ucundan koronale doğru devamlı değişen açılarla üretildikleri için eğenin boyun kısmına yakın bölgedeki açısı $0.85^{\prime}$ e denk gelmektedir. Eğenin bu özelliği koronal bölgede şekillendirme için daha iyi bir genişletme sağlamaktadır. 300 rpm'de ve $2 \mathrm{~N} / \mathrm{cm}^{\prime}$ lik tork derecesinde kullanılması üretici firma tarafından önerilmiştir.

HyFlex GPF (Coltene/Whaledent Inc, Cuyahoga Falls, $\mathrm{OH}$ )

$\mathrm{Bu}$ eğe sistemi $\mathrm{Ni}-\mathrm{Ti}$ alaşımının termo mekanik bir işlemden geçirilerek Controlled Memory (CM) adı verilen bir teknoloji ile üretilmiştir. CM ile üretilen bu eğeler şekil hafızasına sahip olmayıp, çok daha esnek aletlerdir. ${ }^{25}$ Eğeler paslanmaz çelikte olduğu gibi ön ceden bükülebilir . Özellikle ani kavislerin bulunduğu kök kana llarında, bu özellik basamak oluşmasının ön lenmesini sağlayabilir. Eğelerin üzerinde oluşan deformiteler otoklava girdikten sonra düzelmektedir. Düzelmeyen eğelerin tekrar kullanılmaması gerekmektedir. Eğe sisteminde rehber yol oluşturmak için 10/0.01, 10/0.02, 20/0.02 olmak üzere 3 farklı boyutta eğe vardır. ${ }^{26}$

\section{ScoutRace (FKG Dentaire, La Chaux-de- Fonds, Switzerland)}

10/0.02, 15/0.02, 20/0.02 boyutlarında 3 farklı eğesi vardır. Eğelere elektrokimyasal yüzey parlatma işlemi uygulanmıştır ve böylece dayanıklıkları arttırılmaya çalışılmışır. Üzerinde bulunan güvenlik bellek diski sayesinde kullanım sayısını belirleyerek metal yorgunluğunu kontrol edebiliriz. 21,25 ve $31 \mathrm{~mm}$ uzunlukta eğeleri mevcuttur. Eğelerin 800-600 rpm hızla ve $1 \mathrm{~N} / \mathrm{cm}$ tork ayarında kullanılması üretici firma tarafından önerilmiştir. 


\section{One G (Micro-Mega, Besançon, France)}

One $\mathrm{G}$ rehber yol oluşturmayı sağlayan tek eğe sistemidir. $0.14 \mathrm{~mm}$ uç çapı vardır ve eğenin taperı $\% 3$ tür. 21, 25 ve $29 \mathrm{~mm}$ üç farklı boyda üretilmiştir. Kesici kenar üzerindeki değişken oyuklar eğenin vidalama etkisini azaltmaktadır. Eğenin asimetrik çapraz kesitli 3 kesici kenarı vardır. 3 kesici kenarın 3 farkı çapı olması daha etkili debris eliminasyonu için yer sağlar. Tek eğe sistemi ise daha hızlı rehber yol oluşturulmasını sağlar.

\section{R-Pilot (VDW, Munich, Germany)}

R-pilot resiprokal hareket ile çalsşan ilk $\mathrm{Ni}$-Ti döner eğedir. Eğe M-Wire alaşımından yapılmıştır ve tek eğe ile rehber yol oluşturulmasını sağlar. Eğenin uç çapı 0.125 mm'dir ve \%4 taper açısına sahiptir. 21, 25 ve $31 \mathrm{~mm}$ uzunlukta eğeleri mevcuttur. Maillefer)

WaveOne Gold Glider

WaveOne Gold Glider tek kullanımlık tek eğedir ve resiprokal hareket ile çalışmaktadır. Gold-wire metalurji ile üretilmiştir ve eğenin uç kısmında $\% 2$ taper ile başlayan ve koranalde $\% 6$ olan bir taper a sahiptir. Eğenin uç çapı 0.15 mm'dir. Gold-wire teknoloji eğenin esnekliğini arttırmış ve döngüsel yorgunluğa karşı direncini ısıl işlem görmemiş eğelere göre karşılaştırıldığında arttırmıştır. ${ }^{27}$

Rehber yol oluşturmak için kullanılan döner $\mathrm{Ni}$ $\mathrm{Ti}$ eğelerin şekillendirme etkinlikleri çekilmiş insan dişleri ve şeffaf bloklarda araştırılmıştır. Kirchoff ve arkadaşlarının micro-ct kullanarak yaptıkları çalışmada apikal transportasyon açısından Pathfile ve ProGlider eğelerinin benzer sonuçlar gösterdiğini bildirmişlerdir. Şekillendirme zamanı açısından ise Proglider ile daha kısa sürede şekillendirme yapıldığı sonucuna varmışlardır. ${ }^{28}$ Özyürek ve arkadaşlarının PathFile, ProGlider ve $K$ file eğelerinin şekillendirme etkinliklerini değerlendirdikleri bir çalışmada ise kanaldan sapma miktarı ile ilgili bu eğelerin arasında anlamlı bir farklılık bulamamışlardır. ${ }^{29}$ Rehber yol oluşturulmasında eğelerin şekillendirme zamanlarının karşılaştırıldığı başka bir çalışmada ise yine ProGlider eğesinin $G$ file ve $K$ file eğelerinden daha hızlı rehber yol oluşturabildiğini gösterilmiştir. ${ }^{30}$ Alovisi ve ark. çekilmiş dişlerde ProGlider, PathFile ve $\mathrm{K}$ file ile rehber yol oluşturduktan sonra ProTaper Next X2 ile genişletmeyi tamamlamışlar ve şekillendirme sonunda micro-ct kullanarak kanal transportasyonu açısından eğeleri karşılaştırmışlar ve ProGlider eğesinin anlamlı şekilde daha az kanal transportasyonuna yol açtı̆̆ı sonucuna varmışlardır. ${ }^{31}$

Rehber yol oluşturan eğelerin döngüsel yorgun- luğa karşı dayanıklııılarının test edildiği bir çok çalışma vardır. Özellikle eğri ve s-şekilli kanallarda kullanııı̆ı için eğelerin bu kanallarda kırılmaya karşı dirençleri önemlidir. Hyflex, ProGlider, Scout Race, PathFile ve G file eğelerinin döngüsel yorgunluğa karşı direnç- lerinin karşılaştırılığı çalışmada Hyflex eğesinin en dirençli olduğu gösterilmiştir. ${ }^{32}$ Bir diğer çalışmada ise Proglider eğesinin Pathfile ve Scout Race eğelerine göre S-şekilli kanallarda döngüsel yorgunluğa karşı daha dirençli olduğu gösterilmiştir. ${ }^{33}$ Resiprokal hareket ile kullanılan $\mathrm{R}$ pilot eğesinin, rotasyon hareketi ile çalışan Hyflex ve Pathfile eğelerine göre döngüsel yorgunluk direncinin daha yüksek olduğu gösterilmiştir. ${ }^{34}$

Sonuç olarak, rehber yol oluşturmak için farklı özellikte $\mathrm{Ni}-\mathrm{Ti}$ sistemler üretilmeğe ve klinikte en ideal kullanılabilecek eğe sistemini belirleyebilmek için invivo ve in-vitro çalışmalar devam etmektedir. Klinisyenlerin özellikle eğri köklü dişlerde rehber yol oluşturması daha ideal ve başarılı kanal tedavileri için tavsiye edilmektedir.

\section{Damla ÖZSU KIRICI ORCID ID: 0000-0001-8391-1034 Meltem ÇOLAK ORCID ID: 0000-0001-5472-677X}

\section{KAYNAKLAR}

1. Schilder $\mathrm{H}$. Cleaning and shaping the root canal. Dent Clin North Am 1974; 18: 269-96.

2. Tsesis $I$, et al. Prevalence and associated periodontal status of teeth with root perforation: a retrospective study of 2,002 patients' medical records. J Endod 2010; 36: 797-800.

3. Aydin B, Kose T, Caliskan MK. Effectiveness of HERO 642 versus Hedstrom files for removing gutta-percha fillings in curved root canals: an ex vivo study. Int Endod J 2009; 42: 1050-6.

4. Cuje J., C. Bargholz, and M. Hulsmann, The outcome of retained instrument removal in a specialist practice. Int Endod J 2010; 43: 545-54.

5. Wilcox LR, Roskelley C, Sutton T. The relationship of root canal enlargement to finger-spreader induced vertical root fracture. J Endod 1997; 23: 533-4.

6. Wildey WL, Senia ES, Montgomery S. Another look at root canal instrumentation. Oral Surg Oral Med Oral Pathol 1992; 74: 499-507.

7. Cunningham CJ, Senia ES. A three-dimensional study of canal curvatures in the mesial roots of mandibular molars. J Endod 1992; 18: 294-300.

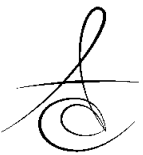


8. Schafer $E$, Vlassis M. Comparative investigation of two rotary nickel-titanium instruments: ProTaper versus RaCe. Part 1 . Shaping ability in simulated curved canals. Int Endod J 2004; 37: 229-38.

9. Jafarzadeh $\mathrm{H}$. Abbott $\mathrm{V}$. Ledge formation: review of a great challenge in endodontics. J Endod 2007; 33: 1155-62.

10. Allen MJ, Glickman GN, Griggs JA. Comparative analysis of endodontic pathfinders. J Endod 2007; 33: 723-6.

11. Berutti $E$, et al. Influence of manual preflaring and torque on the failure rate of ProTaper rotary instruments. J Endod 2004; 30: 228-30.

12. Berutti $E$, et al. Use of nickel-titanium rotary PathFile to create the glide path: comparison with manual preflaring in simulated root canals. J Endod 2009; 35: 408-12.

13. Patino $V$, et al. The influence of a manual glide path on the separation rate of $\mathrm{NiTi}$ rotary instruments. J Endod 2005; 31: 114-6.

14. D'Amario M., et al., Evaluation of a new nickeltitanium system to create the glide path in root canal preparation of curved canals. J Endod 2013; 39: 1581-4.

15. West J. Endodontic update 2006. J Esthet Restor Dent 2006;18: 280-300.

16. Kanika Aggarwal1, SSL, Monika Chaudhary3, Amandeep Singh Arora4, Manmit Kaur5, Mayank Kakkar6, An Endodontic Glidepath- A Step to Safe Rotary Practice. Int J Dent Medical Res 2014;

17. Peters O.A. and F. Paque, Current developments in rotary root canal instrument technology and clinical use: a review. Quintessence Int 2010; 41: 479-88.

18. Young G.R., Parashos, and H.H. Messer, The principles of techniques for cleaning root canals. Aust Dent J, 2007; 52: S52-63.

19. Roland DD, et al. The effect of preflaring on the rates of separation for 0.04 taper nickel titanium rotary instruments. J Endod 2002; 28: 543-5.

20. Peters OA, et al. ProTaper rotary root canal preparation: assessment of torque and force in relation to canal anatomy. Int Endod J 2003; 36: 93-9.

21. Mounce R. Endodontic K-files: invaluable endangered species or ready for the Smithsonian? Dent Today, 2005. 24: 102, 104.

22. West J. The endodontic glide path: "Secret to rotary safety". Dent Today, 2010; 29: 86-93.
23. Kinsey B, Safe MR. Efficient use of the M4 safety handpiece in endodontics. Roots 2008; 4: 36-40.

24. http://www.dentsplymaillefer.com/-/218x624/ line218x 7950/product_218x9225. [cited 2014 Accessed June 15,].

25. Seago ST, et al., Effect of repeated simulated clinical use and sterilization on the cutting efficiency and flexibility of Hyflex CM nickeltitanium rotary files. J Endod 2015; 41: 725-8.

26.https://www.coltene.com/fileadmin/Data/EN/Produ cts/Endodontics/Root_Canal_Shaping/HyFlex_CM/ HyFlex_CM_-_TR.pdf.

27. http://www.endoruddle.com/GoldGlider.

28. Kirchhoff $A L$, et al. Glide Path Management with Single- and Multiple-instrument Rotary Systems in Curved Canals: A Micro-Computed Tomographic Study. J Endod 2015; 41: 1880-3.

29.Özyürek T, Uslu G, Yılmaz K. Rehber yolu oluşturulmasında farklı eğe sistemlerinin etkinliklerinin karşılaştırılması. Atatürk Üniv Diş Hek Fak Derg 2018; 1:13-7

30. Paleker F, van der Vyver J. Glide Path Enlargement of Mandibular Molar Canals by Using K-files, the ProGlider File, and G-Files: A Comparative Study of the Preparation Times. J Endod 2017;43: 609-12.

31. Alovisi $M$, et al. Micro-CT evaluation of several glide path techniques and ProTaper Next shaping outcomes in maxillary first molar curved canals. Int Endod J 2017; 50: 387-97.

32. Capar ID, et al. Comparison of the cyclic fatigue resistance of 5 different rotary pathfinding instruments made of conventional nickel-titanium wire, M-wire, and controlled memory wire. J Endod 2015; 41: 535-8.

33. Topcuoglu HS, Topcuoglu G, Duzgun S. Resistance to cyclic fatigue of PathFile, ScoutRaCe and ProGlider glide path files in an S-shaped canal. Int Endod J 2018; 51:509-4

34. Uslu G, et al. Cyclic fatigue resistance of R-Pilot, HyFlex EDM and PathFile nickel-titanium glide path files in artificial canals with double (S-shaped) curvature. Int Endod J 2018; 51:584-9
Yazışma Adresi
Damla Özsu Kırıcı
Akdeniz Üniversitesi Endodonti Anabilim Dalı
Antalya, Türkiye
Tel: 0508168470
e-mail adresi: d_ozsu@hotmail.com 